\title{
OS DESAFIOS DA EDUCAÇÃO AMBIENTAL EM UM BRASIL DESCONHECIDO NA VISÃO DE ACADÊMICOS DE PEDAGOGIA EM JAPURÁ (AM)
}

\author{
THE CHALLENGES OF ENVIRONMENTAL EDUCATION IN AN UNKNOWN \\ BRAZIL IN THE VIEW OF SCHOLARS OF PEDAGOGY IN JAPURÁ
}

Priscila Eduarda Dessimoni Morhy ${ }^{1}$

ORCID iD: 0000-0002-3298-2315

Felipe da Costa Negrão ${ }^{2}$

ORCID iD: 0000-0001-6840-6670

\section{RESUMO}

A Educação Ambiental é uma via real de enfrentamento aos problemas atuais que envolvem pessoas, recursos naturais e a biodiversidade. $\mathrm{O}$ incentivo e/ou desenvolvimento dela, com efetividade, é responsabilidade também da escola; logo, os cursos de formação de professores precisam oportunizar tal aprendizado aos futuros docentes. Este trabalho apresenta os resultados de um questionário aplicado a acadêmicos de Pedagogia do PARFOR de Japurá (AM), regularmente matriculados na disciplina de Ciências da Natureza na Educação Infantil e Anos Iniciais do Ensino Fundamental. Os resultados apontam para o reconhecimento das necessidades reais do município que sofre com problemas de descarte do lixo e saneamento básico, além de desvelar que os acadêmicos desconhecem a legislação educacional. $\mathrm{O}$ trabalho defende uma formação de professores que sejam profissionais engajados em questões ambientais, principalmente por estarmos inseridos na Amazônia, berço da biodiversidade do mundo. A pesquisa revela o reconhecimento dos acadêmicos acerca da importância do ensino de ciências para a formação de professores, consequentemente, para a formação de cidadãos críticos, responsáveis e reflexivos.

Palavras-chave: Educação Ambiental. Sustentabilidade. PARFOR.

\begin{abstract}
Environmental Education is a real way of tackling current problems involving people, natural resources and biodiversity. The incentive and / or development of it, effectively, is also the responsibility of the school; therefore, teacher training courses need to provide future teachers with such learning. This paper presents the results of a questionnaire applied to students of Pedagogy at PARFOR de Japurá (AM), regularly enrolled in the discipline of Natural Sciences in Early Childhood Education and Elementary Years. The results point to the recognition of the real needs of the municipality that suffers from problems of waste disposal and basic sanitation, in addition to revealing that academics are unaware of educational legislation. The work defends the formation of teachers who are professionals engaged in environmental issues, mainly because we are inserted in the Amazon, the cradle of the world's biodiversity. The research reveals the recognition of academics about the importance of science

\footnotetext{
${ }^{1}$ Mestre em Educação em Ciências na Amazônia pela Universidade do Estado do Amazonas (UEA). Professora do Centro Universitário do Norte (UNINORTE), Manaus, Amazonas, Brasil. Endereço para correspondência: Rua Jorge Luiz Milani, 640, Flores, Manaus, Amazonas, Brasil, CEP: 69058-828. E-mail: primorhy@ hotmail.com. ${ }^{2}$ Mestre em Educação em Ciências na Amazônia pela Universidade do Estado do Amazonas (UEA). Professor do Departamento de Métodos e Técnicas da Universidade Federal do Amazonas (UFAM), Manaus, Amazonas, Brasil. Endereço para correspondência: Rua Coreau, 10, Qd 64, São José Operário, Manaus, Amazonas, Brasil, CEP: 69086-161. E-mail: felipe.unl@ hotmail.com.
} 
education for teacher training, consequently, for the formation of critical, responsible and reflective citizens.

Keywords: Environmental Education. Sustainability. PARFOR.

\section{INTRODUÇÃO}

A Educação Ambiental (EA) é concebida atualmente como uma via de possibilidades para transformações de atitudes e posturas frente às crises socioambientais que a sociedade vem passando. O desenvolvimento de uma postura coerente com essa temática permite que o indivíduo forme-se no sentido social, cultural, profissional e pessoal. Desse modo, contribua exponencialmente ao bem-estar individual, coletivo e ambiental.

No Brasil há uma rica diversidade de culturas, ambientes e modos de vida que proporcionam desenvolver uma EA metodologicamente inovadora, sendo possível a construção de pontes reflexivas para a formação de pessoas sementes ${ }^{3}$ que dialogam de forma positiva na educação com as diversas realidades (culturais, ambientais e econômicas) que o país apresenta.

Entretanto, falar e desenvolver práticas de EA que emancipem a humanidade para um planeta verdadeiramente sustentável, seria mera utopia? Ao pensarmos essa questão é fundamental refletirmos sobre a realidade educacional brasileira (educação básica e superior) a qual vivenciamos boa parte de nossa existência.

Em alguns casos, a educação básica torna-se reflexo de uma educação superior fragmentada, em que o pedagogo em formação apresenta carência no contato com temas e/ou assuntos que produzam conhecimento científico para resoluções de problemas ambientais. Além disso, é observável a falta de interação e (re)conexão com o ambiente a partir de práticas educativas em espaços não formais de ensino, sendo estes excelentes lugares para a construção do conhecimento e a sensibilização ambiental. Em suma, tal fragmentação resulta na falta de experiência, desconhecimento de práticas e legislações que promovam um ensino interdisciplinar e transdisciplinar, impactando negativamente no desenvolvimento de atividades pedagógicas holísticas que levem em consideração o indivíduo em sua totalidade (ambiental, cultural e econômico).

\footnotetext{
${ }^{3}$ Propagam atitudes positivas em relação à natureza e às pessoas, espalham - por onde passam - conhecimentos científicos sem minimizar a importância do vínculo afetivo entre seres humanos e ambiente (MORHY, 2018).
} 
A valoração desta perspectiva de educação bancária está ancorada na transmissão do conhecimento científico, de modo racional, lógico e cognitivo. Ele não minimiza a importância de tais aspectos, haja vista que sabemos que, para a constituição do indivíduo como seres complexos que somos, as dimensões humanas vão além das atividades cotidianas escolares. Em outras palavras, somos seres compostos por relações "esteticus, ludens, demens, ético, filosófico, histórico e cultural [...] que não são passíveis de enquadramento nos marcos reducionistas da produção de conhecimento científico" (BARCELOS, 2012, p. 53).

Formar novos professores é um desafio diário em um país que desvaloriza a profissão, seja na esfera econômica, política, ou ainda no campo social, estigmatizando e reduzindo a profissão docente a mera vocação. Sendo assim, existem percalços que precisam ser vencidos frente a uma nova geração de docentes que possuem a responsabilidade social de educar um futuro que já começa no agora.

Nossa pesquisa debruça-se sobre o "Programa Nacional de Formação de Professores da Educação Básica (PARFOR)”, este contribui de forma positiva para a formação de professores em cidades e/ou comunidades longínquas em todo país; contudo, este estudo evidencia a realidade do Estado do Amazonas.

Dessa maneira, a coleta de dados ocorreu no município de Japurá (AM), e deparou-se com inúmeras adversidades corriqueiras de cidade pequena, tais como: a escassez de recursos, precariedade das escolas onde ocorrem as aulas, além da falta de investimento em saneamento básico. Contudo, frente a tudo isso, percebe-se que os estudantes do PARFOR manifestam interesse e determinação em aprender sobre EA, considerando-a ferramenta de transformação social, política e econômica.

A Educação Ambiental pode e deve estar associada à ciência como base para o desenvolvimento e amadurecimento da sociedade, estando intimamente ligada às relações, experiências e vivências da própria humanidade, tanto em suas questões sociais e culturais, quanto nas relações emocionais e afetivas. Porém, observa-se que a concepção dela ainda está relacionada apenas à preservação e à conservação da natureza, devendo-se incluir o homem como parte do meio, sujeito ativo e contribuinte para uma sociedade equânime e inclusiva.

Neste sentido, em um país com vasta territorialidade como o Brasil, percebemos que existem lugares intocados cientificamente (produção do conhecimento), como é o caso do município de Japurá, que faz fronteira com a Colômbia, no interior do Amazonas, Estado este 
conhecido por sua grande biodiversidade e sua exuberância de fauna e flora, mas que ainda assim abarca inúmeros desafios para o desenvolvimento da EA.

Por ser uma cidade longínqua, o deslocamento para Japurá pode perdurar por semanas, mas esse se torna o menor dos problemas ao se chegar na cidade, isto é, à medida que se percebe o quanto as condições para a construção do saber são precárias, a escassez de recursos humanos, didáticos, pedagógicos, tecnológicos, psicológicos e emocionais são constituintes da realidade observada. Em outros termos, um Brasil desconhecido, com problemas sociais complexos, onde as características do local revelam verdadeiramente as dificuldades e desafios aos quais enfrentamos ao tratar das questões ambientais.

A expectativa é que este trabalho apresente um mapeamento da realidade atual e emergente de Japurá, no que se refere às questões de formação de professores e educação ambiental, ou seja, a fim de que se pense em estratégias de intervenção que tragam visibilidade aos problemas ambientais e despontem-se em políticas públicas de conservação, preservação e restauração do local, oportunizando uma melhor qualidade de vida aos moradores.

\section{EDUCAÇÃO AMBIENTAL: PRINCÍPIOS E FORMAÇÃO DE PROFESSORES}

Ao discutir, descrever ou escrever sobre EA é comum que surjam dúvidas em relação aos conceitos e definições da própria nomenclatura. Sendo assim, acredita-se que a melhor definição para tal questão é a de Reigota (2017, p. 13) que a define como: "educação política" e "pedagógica" justamente por abarcar os aspectos econômico, social e cultural "entre a humanidade e a natureza e as relações entre os seres humanos, visando a superação dos mecanismos de controle e de dominação que impedem a participação livre, consciente e democrática de todos".

Neste viés, falar e trabalhar com EA na Amazônia não só é um ato político, como também humanitário. Via de regra, em cidades muito distantes, o básico torna-se luxo e o conhecimento científico e tecnológico, por vezes, é escasso. Assim, ainda é notório em alguns ambientes formais de ensino que EA é abordada meramente em práticas educativas realizadas em datas comemorativas, ou seja, em uma música cantada ou uma história falada.

Nota-se que não há uma concepção real do quão profundo a EA é, bem como nega-se o fato de que nossas relações e interações com o ambiente, positiva ou negativamente, afetam de 
forma direta no nosso modo de vida, pois a educação é uma via de contribuição social, econômica e ambiental, principalmente para os mais necessitados em nosso país.

Dessa forma, é fundamental explanarmos sobre educação e as práticas de EA que, por conseguinte, são reflexos da formação dos professores. Assim, a qualidade no ensino abrange aspectos históricos e sociais fundamentais na atualidade e afetam positivamente ou não a qualidade da educação escolar brasileira.

Neste sentido, a partir dos anos 90 surge uma nova cadeia de ações que possibilitam a qualificação docente de forma permanente e ativa. A Lei de Diretrizes e Bases da Educação (LDB), no 9.394 de 1996, destaca-se por garantir que todo e qualquer docente da educação básica gradue-se em licenciatura plena em "universidades" e/ou "institutos superiores de educação".

Dessa maneira, temáticas vinculadas aos assuntos ambientais ainda são obstáculos presentes nos cursos de formação de professores, tendo em vista que boa parte das discussões se reduzem aos temas transversais presentes em disciplinas como: Currículo e Políticas Públicas. Em suma, é tímido o movimento que defende e institucionaliza a Educação Ambiental enquanto disciplina obrigatória no curso de Pedagogia, por exemplo.

Em nossa experiência, contamos com uma matriz curricular que respeita e dignifica a essência de ser do Norte do país, uma vez que insere essas discussões em um curso e em localidades que precisam tanto de conhecimento científico quanto do prático, a fim de melhorar a própria qualidade de vida das pessoas.

Brezinski (2014, p. 1243) enfatiza sobre os principais aspectos que desafiam e postergam uma formação docente adequada.

\footnotetext{
Na definição e desenvolvimento das políticas de formação de profissionais da educação, constata-se, contudo, que o governo nas duas últimas décadas opta por práticas de políticas pontuais e emergenciais, por meio de planos e programas dispersos, marcados pela inorganicidade e desarticulação do próprio Ministério da Educação (MEC). No âmbito dessas políticas, ignora-se a importância de um controle social sistemático, o que implica malversação de recursos públicos. Na verdade, não existe uma política pública global de formação e valorização dos profissionais da educação, de modo que se articule a qualidade social dos processos formativos com condições dignas de trabalho, carreira e planos de cargos e salários com base no piso salarial nacional
}

Esses aspectos contribuem para uma formação docente fragmentada, pois o próprio Estado do Amazonas, berço esplêndido de grande biodiversidade e riquezas culturais, não está longe de tais contratempos que dificultam o trabalho do educador e somatizam problemas no exercer da profissão. 
É fundamental que os futuros docentes enquanto agentes sociais transformadores, formados pelo PARFOR, saibam "saber fazer" didaticamente, pois sua função é facilitar o processo de conhecimento e de amadurecimento cognitivo do estudante, estabelecendo relações reais do indivíduo com o ambiente inteiro. Com efeito, ele se redescubra como parte do problema e também da solução.

Por isso é tão importante formar professores capazes de construírem, significativamente, o conhecimento; para assim, mudar, inovar e transformar a realidade pautando-se em uma ciência que valoriza aspectos subjetivos dos seres humanos, uma vez que a EA "deve ser trabalhada de forma interdisciplinar, promovendo uma compreensão abrangente dos diferentes objetos de conhecimento, abrindo espaço para a inclusão de saberes extraescolares" (DE SOUZA, 2012, p. 110).

Mas quais as necessidades reais de professores que formam-se em cidades e/ou municípios do Amazonas a quilômetros de distância da capital? Os desafios enfrentados diariamente são grandes, visto que para chegar a uma cidade que promove a formação de educadores pode-se levar mais de 12 horas, dias e até semanas.

Quando se trata de Amazônia, remetemos-nos à fauna, à flora, ao povo encantador, este alegre e inebriado de uma cultura ímpar de pertencimento à natureza. Entretanto, há ambientes (lugares, comunidades, cidades) que apresentam "precárias condições civis, sanitárias, educacionais, ambientais, econômicas, de saúde, etc que não combinam com as falácias sobre sustentabilidade na Amazônia tão anunciadas, inclusive pelo governo" (VASCONCELOS, 2016, p. 163).

Nesta perspectiva é impossível falar em desenvolvimento regional sem conectarmos a educação ambiental à formação de professores, a qual no interior do Amazonas tem início no PARFOR, este como instrumento formador base para o ser docente. Essa formação é um sopro de esperança social e democrática; afinal, são cursos de graduação nas áreas de licenciatura que carregam consigo o sonho de (re)evolução, pois em sua maioria são alunos que desejam fortemente transformar a realidade da comunidade onde vivem (econômica, cultural e ambiental). Em suas visões, o PARFOR tem o poder de transformar vidas. Assim:

Deseja-se que os professores reconheçam o potencial transformador do seu trabalho. Só assim, eles e todos os profissionais do saber serão capazes de interagir, tanto no mundo acadêmico, quanto no mundo social. Por isso, propõe-se o engajamento do cursos de Licenciatura e suas discussões e projetos nas questões de preservação do meio ambiente (DE SOUZA, 2012, p. 111). 
O PARFOR é um programa de formação não só para os alunos, como também para os docentes, pois ensinar é aprender de maneira coletiva e colaborativa. Os professores formadores perpassam por inúmeras dificuldades para chegar às localidades a que são destinados. Muitos viajam de barcos, lanchas e até ambulanchas (ambulância em formato de lancha para moradores doentes dos interiores do Amazonas), uma vez que nossas estradas são feitas de água. Há ainda privações como hospedagem precária, além da falta de materiais tecnológicos e didáticos para ministrar as aulas, dentre outros percalços.

Entretanto, é engrandecedora a força desse programa na conjectura sociopolítica da atualidade no Brasil. Isto significa afirmar que mediante um cenário do Brasil desconhecido, o PARFOR possibilita que sonhos sejam idealizados e objetivos alcançados, e assim a educação básica do Brasil ganha jovens professores com força e alegria de exercerem a profissão. Nisto, nós formadores ganhamos uma experiência inigualável de se dispor e vivenciar parte de uma realidade a qual não estamos acostumados, mas que fora forjado em essência, cuja missão é a de ser professor.

Por este motivo, enquanto professores e graduandos de licenciaturas, é nosso dever rever nossos valores, trabalhar em prol da ética, e (re)afirmar nosso compromisso com a educação de modo que precisamos refletir se seremos somente meros transmissores de conteúdo e ceder-nos ao sistema individualista, preconceituoso e discriminatório. que - por vezes - prevalece na sociedade. Ou ainda, se lutaremos por mudanças que modifiquem a realidade dos estudantes a partir de práticas pedagógicas inovadoras, metodologia criativas, trabalhos inter e transdisciplinares que contribuam para uma consciência crítica.

Em outras palavras, o exercício e a função docente deve compreender a realidade do mundo, incentivando o desenvolvimento de pessoas, a fim de que elas possam se tornar questionadoras, com expertise para a solução de problemas em prol da humanidade e de todos os seres vivos do planeta.

\section{METODOLOGIA}

O artigo ancora-se nos preceitos da pesquisa descritiva (FONSECA, 2010), uma vez que sugere reflexões a partir de ações vividas em espaço profissional, sendo relevante a comunicação à comunidade científica (CAVALCANTE; LIMA, 2012). A coleta de dados deu-se através da aplicação de um questionário com quatro perguntas abertas. 
O locus da pesquisa é o município de Japurá, cidade rodeada de um extremo a outro, pelo rio homônimo, afluente do rio Solimões, possuindo uma população de 2.755 pessoas (IBGE, 2019). Dentre essa população, nosso estudo debruça-se no âmbito do PARFOR, enquanto curso que forma novos professores para o município. Sendo assim, o questionário foi aplicado com 32 alunos matriculados na disciplina "Ciências da Natureza na Educação Infantil e Anos Iniciais do Ensino Fundamental" do curso de Pedagogia, ofertado pela Universidade do Estado do Amazonas (UEA).

Os acadêmicos, em sua maioria, não residem no município, mas em comunidades tradicionais e ribeirinhas, sendo necessário enfrentar até três dias de barco ou lancha para chegar até a cidade de Japurá. Os colaboradores desta pesquisa possuem faixa etária de 25 a 40 anos e na época da coleta de dados estavam no quarto período do curso de Pedagogia.

As aulas ocorrem em um polo da UEA localizado em um escola pública da Rede Estadual. A infraestrutura é precária, havendo infiltrações que aumentam em períodos de chuva, acentuando também o mofo devido a umidade, um fator climático da Região Norte.

A cortina improvisada com papel-madeira auxilia na visão das aulas projetadas no data show, uma vez que as aulas ocorrem no período diurno, horário em que a luminosidade é alta e dificulta a visibilidade do material disponibilizado pelo professor formador. Há ainda carência de diversos materiais de papelaria, tais como: carteiras, livros e principalmente a internet, uma vez que o município não dispõe de conexões tão boas, impactando diretamente nas pesquisas e leituras inerentes ao universo acadêmico, principalmente em um curso que forma professores.

A disciplina tem carga-horária de 60 horas/aula, sendo distribuída em sete dias com aulas teóricas e práticas, além de atividade integradora que incluiu a comunidade como parte ativa do processo de construção de conhecimento.

A ementa da disciplina abarca temas importantes para a discussão e participação dos estudantes sobre questões ambientais, trazendo suas realidades e experiências como ponto de partida nos espaços educativos de ensino, de modo que os assuntos abordados foram: $\mathrm{O}$ ambiente e os seres vivos; A água; $\mathrm{O}$ ar; $\mathrm{O}$ solo; $\mathrm{O}$ ciclo vital de animais e plantas: classificação, características, tipos de alimentação e habitat; O equilíbrio ecológico; Os alimentos: tipos e origens, seleção, armazenamento, preparo e consumo; Saúde e higiene ambiental: coleta e reciclagem do lixo; saneamento básico; Recursos Técnicos e Tecnológicos; Eletricidade: obtenção e distribuição. 
Os questionários eram compostos de quatro questões abertas e as respostas foram lidas, analisadas e tabuladas a partir do que prescreve a análise de conteúdo (BARDIN, 2016), uma vez que esta recomenda uma "descrição objetiva e sistemática" nos aspectos de organização, transcrição e levantamento de categorias.

Para fins de análise, utilizamos das pré-análise, exploração do material e tratamento de dados junto a literatura. Desta maneira, elencamos quatro categorias oriundas do questionário, a saber: a) importância das ciências da natureza; b) conteúdos e temas de ciências da natureza; c) dificuldades enfrentadas por professores; e d) legislação educacional.

\title{
4 ANÁLISES E RESULTADOS
}

A primeira categoria refere-se a importância das Ciências da Natureza para a Educação Infantil e os Anos Iniciais, de modo que as respostas apresentam em demasia uma perspectiva de respeito à natureza, à educação ambiental e à ampliação da visão de mundo da criança. Em poucas respostas, viu-se a presença da CTS (Ciência, Tecnologia e Sociedade) e do próprio conhecimento científico.

A consciência crítica sobre os problemas ambientais é cada vez mais urgente em nossa sociedade, para isso a escola pode ser contribuinte na propagação dessa ideia de pertencimento e responsabilidade ambiental.

\begin{abstract}
O relacionamento da humanidade com a natureza tem culminado em fonte de forte pressão sobre os recursos naturais, tornando-se rotina mundial a contaminação dos cursos de água, a poluição atmosférica, a caça indiscriminada, a devastação de florestas e outros ambientes naturais, além de muitas outras formas de agressão. Essa realidade torna clara e imediata reflexões e ações que mudem esse comportamento, promovendo modelos de desenvolvimento sustentável e a prática de atitudes ao mesmo tempo econômicas e preservacionistas, com esperança de reflexos positivos e evidentes junto à qualidade de vida para todos (SELBACH, 2010, pp. 64-65).
\end{abstract}

Nesse sentido, para os acadêmicos, o ensino de ciências da natureza oportuniza também um olhar crítico para a realidade local do município, sendo que nesse item destacamos que Japurá carece de atenções por parte do poder público, uma vez que a cidade possui um sistema de saneamento básico precário e muitos problemas nessa instância como o descarte do lixo.

A ciência enquanto contribuinte para o aguçar da curiosidade da criança também esteve presente nas respostas, sendo esta essencial na Educação Infantil, primeira etapa da educação básica que não trabalha com disciplinas, e sim com experiências. Logo, pensar em ciências na 
Educação Infantil é pensar em experiências, vivências e práticas pedagógicas que envolvam resolução de problemas, criatividade e criticidade.

Portanto, a Educação Infantil deve promover:

\begin{abstract}
O conhecimento de si e do mundo por meio da ampliação de experiências sensoriais, expressivas, corporais que possibilitem movimentação ampla, expressão da individualidade e respeito pelos ritmos e desejos da criança; Possibilitem situações de aprendizagem mediadas para a elaboração da autonomia das crianças nas ações de cuidado pessoal, auto-organização, saúde e bem-estar; Incentivem a curiosidade, a exploração, o encantamento, o questionamento, a indagação e o conhecimento das crianças em relação ao mundo físico e social, ao tempo e à natureza; Promovam a interação, o cuidado, a preservação e o conhecimento da biodiversidade e da sustentabilidade da vida na Terra, assim como o não desperdício dos recursos naturais. (BRASIL, 2010, p.21-22).
\end{abstract}

A formação de professores deve oportunizar saberes que permitam que o futuro docente possua embasamento teórico e prático para o desenvolvimento das ações listadas nas diretrizes curriculares. Enquanto professores formadores, temos que assumir o compromisso com os conteúdos, respeitando as normativas nacionais, além de aproximarmos nossa fala dos campos de atuação desse profissional.

A segunda categoria enfatiza os conteúdos e temas de ciências da natureza e refere-se ao fato de os acadêmicos acreditarem em serem essenciais na Educação Infantil e Anos Iniciais. O destaque das respostas está na reciclagem e no lixo, de modo que parece ser mesmo um problema público do município, abrindo espaço para possíveis intervenções em disciplinas futuras, tais como a própria educação ambiental.

Na visão de Trivelato e Silva (2011, p. 13):

A educação ambiental vem se consolidando como uma prática educativa integrada, que pode correr em diversos contextos, podendo oferecer uma contribuição muito grande ao processo educativo em geral e à formação de cidadãos mais conscientes do seu papel na sociedade, em relação aos outros e ao meio ambiente.

Meio ambiente, água, seres vivos, corpo humano, solo, plantas, ar e poluição foram os temas apresentados nas respostas dos acadêmicos, sendo estes essenciais às aulas de ciências. Reigota (1995) classificou as representações sociais mais prevalentes de meio ambiente, de modo que os conteúdos e temas listados anteriormente se encaixam na vertente naturalista.

Outro dado coletado consiste no conteúdo de higienização dos alimentos e esteve presente em um dos questionários, acreditando-se ser importante tal abordagem para crianças, uma vez que a saúde está atrelada à higiene do corpo e, consequentemente, dos alimentos que 
ingerimos. Na visão de Reigota (1995), essa temática está associada à vertente globalizante que consiste nas interações entre aspectos sociais e naturais.

Assim, a temática da sustentabilidade foi apontada enquanto conteúdo de ciências da natureza e emerge num contexto onde as práticas sustentáveis estão em alta, haja vista os percalços que a humanidade tem passado frente às mudanças climáticas e ao aquecimento global. Sendo assim, uma educação para a sustentabilidade deve orientar crianças e adultos para o consumo consciente e o respeito aos recursos naturais, para que as futuras gerações sejam agraciadas com o uso não escasso da água, por exemplo, e demais recursos.

Para Elali (2003) é urgente e necessária a mudança de discurso frente às questões da sustentabilidade com nossas crianças. E é no ambiente escolar que há a possibilidade de sensibilizarmos os pequeninos para as questões ambientais. Nisto, a ideia de sustentabilidade abriga a vertente antropocêntrica definida por Reigota (1995) como a utilidade dos recursos naturais para a sobrevivência humana.

Paralelo a estes temas e conteúdos, a ideia de diversidade, cultura e valores também foi listada pelos acadêmicos, e sobre isso acreditamos ser possível e necessário o entendimento desses conceitos por parte da criança. E, para isso, indicamos a interdisciplinaridade enquanto ferramenta para promulgação de tais saberes.

Nesse sentido, Fazenda (2005) enfatiza que a interdisciplinaridade quando bem desenvolvida em espaços educativos de ensino deve oportunizar às crianças uma aprendizagem ativa e colaborativa, contribuindo e construindo o conhecimento uns com os outros em prol de um olhar para as resoluções de problemas. Ademais, a interdisciplinaridade não deve ser entendida apenas como conceito e/ou jargão pedagógico, mas também como ação e postura vivenciadas no coletivo de professores que se ajudam, mutuamente, na condição de construtores de conhecimentos diversos e inter-relacionados socialmente (ZANON, 2015).

A terceira categoria apresenta as dificuldades enfrentadas por professores para desenvolvimento dos temas de ensino de ciências na Educação Infantil e nos anos iniciais. Posto isso, a maior dificuldade defendida pelos acadêmicos está na escassez de materiais para o desenvolvimento de aulas práticas, inclusive essa ausência de material é recorrente em qualquer escola de esfera pública. Em outras palavras, exige que o docente utilize de recursos próprios ou se permita trabalhar com materiais alternativos.

Os acadêmicos indicaram também a falta de formação continuada no ensino de ciências, sendo esta fundamental, tendo em vista que uma ou duas disciplinas não nos preparam para o 
pleno exercício do componente curricular; logo, é fundamental que as escolas ofereçam cursos, grupos de estudo e palestras que evoquem o ensino de ciências como objeto de estudos e pesquisas.

Santos (2018, p. 44) afirma que:

A Formação Continuada é, por sua vez, o aporte teórico e científico que visa manter o professor, pós-formado, frente às inovações da Ciência e Tecnologia, em um espaço que valorize a sua experiência, atitudes e comportamentos já vivenciados na realidade de uma escola e que enfrenta diariamente os limites referentes de sua prática, pois se acredita que é por meio de uma reflexão sistemática acerca de seu próprio fazer pedagógico, que o professor seja capaz de mudar e reformular suas ações quando julgar necessário, aprimorando, dessa forma, seu próprio fazer pedagógico.

A falta de apoio institucional, a ausência de nutricionista e a estrutura física das escolas também estiveram presentes nas respostas dos acadêmicos que, por vezes, se veem em graves dificuldades em um ambiente cujas oportunidades são geradas a partir das figuras hierárquicas da direção da escola. Além disso, as pequenas creches em espaços alugados que não foram pensados para ser escola, também prejudicam o desenvolvimentos de aulas significativas, fazendo com que o educador trabalhe com planos alternativos.

A respeito desse assunto, Masullo e Coelho (2015) afirmam que tais dificuldades estruturais e pedagógicas corroboram para práticas de ensino precárias, bem como contribuem para a fragmentação do conhecimento e a não formação de sujeitos críticos/reflexivos. Portanto, cabe refletir e repensar políticas públicas que olhem com mais apreço para a realidade do município de Japurá, uma vez que a universidade tem feito sua parte no envio de docentes formadores para oportunizar uma formação plena aos acadêmicos. Logo, resta ao poder público contribuir de forma significativa com melhores condições de trabalho e aprendizado para seus habitantes.

Por fim, a última categoria apresenta a contribuição da legislação educacional frente à contextualização do ensino de ciências. Nesse item esteve claro que os acadêmicos desconhecem a legislação e documentos normativos da própria área de atuação, tendo em vista as respostas mais generalistas acentuadas pelo próprio enunciado da questão que mencionava as DCNEI, PCNs e BNCC.

Ainda assim, alguns alunos acreditam que a contextualização é essencial, pois aproxima o educando da realidade, fazendo com que a aprendizagem seja mais significativa. Além disso, reforçam que a comunidade científica nem sempre foi a responsável por implementar as leis, 
pelo contrário, por vezes foram construídas por pessoas que não fazem a educação diariamente e que se sentem no direito de opinar e decidir acerca de realidades que não suas.

Os estudantes também defendem a construção de cidadãos críticos e reflexivos. Nisto, todas as leis listadas reforçam e preconizam que tanto a educação infantil e o ensino fundamental devem desenvolver tal fim.

Em suma, boa parte dos acadêmicos associa erroneamente as leis aos livros didáticos, reforçando o discurso de que estes são indicadores para a seleção de conteúdos e temáticas a serem tratadas com os estudantes da educação básica. Contudo, "a aprendizagem não se resume ao livro didático, mas a uma série de fatores que perpassam desde a formação dos professores até o planejamento de aulas atrativas, dentro e fora do espaço escolar". (NEGRÃO et al, 2016, p. 30).

\section{CONSIDERAÇÕES FINAIS}

Uma educação ambiental que transforme a sociedade não deve ser uma ideia utópica, mas um ideal de todo ser humano. As práticas sustentáveis contribuem para a conservação dos recursos naturais para as gerações vindouras e precisam ser encorajadas a partir da escola. Portanto, é tarefa do educador enxertar essa semente de consumo consciente nas crianças.

O Amazonas é o maior estado em extensão geográfica do Brasil, e abriga uma imensa floresta tropical repleta de espécies únicas de fauna e flora, estas que precisam ser resguardadas do próprio homem, este que é sedento por riquezas e benefícios. Assim, as ações dele geram impactos negativos à biodiversidade. Entretanto, o único responsável e capaz de defender nossos recursos naturais parte dele, por isso a educação ambiental deveria ser regra e não opção de nossas escolas.

Observamos ainda que as respostas dos questionários sugerem a necessidade de reais intervenções acerca do ensino de ciências no município de Japurá, e revela-nos os problemas emergentes do lixo e do saneamento básico. Em síntese, apontam ainda para o desconhecimento da legislação educacional, premissa básica para um trabalho docente efetivo e de qualidade.

Os resultados expressam, ainda, a prevalência de conteúdos ligados aos livros didáticos em detrimento daqueles mais direcionados ao contexto local, tais como a prática de reutilização, sustentabilidade e CTS. Por fim, os acadêmicos reconhecem que o ensino de ciências da 
natureza é fundamental para a formação de professores, e consequentemente, para a formação de cidadãos críticos, responsáveis e reflexivos.

Sendo assim, o saber vinculado à Educação Ambiental deve ser compartilhado a partir de uma rede entre graduandos do PARFOR e a comunidade de Japurá, pois o conhecimento deve ser transmutado, construído e reconstruído a partir das vivências e experiências interioranas, caboclas, indígenas e ribeirinhas; inundados de pluralidades e saberes que daqueles que podem expressá-lo e senti-lo.

\section{AGRADECIMENTOS}

Aos alunos do PARFOR, do curso de Pedagogia do município de Japurá, os quais possuem potencial de transformação, que se reinventam todos os dias, que mesmo diante dos obstáculos, resistem e são resilientes, sonham com uma educação de qualidade, com equidade e dignidade para todos.

\section{REFERÊNCIAS}

BRASIL. Lei n. ${ }^{\circ}$ 9394/96. Lei de Diretrizes e Bases da Educação Nacional. Estabelece as diretrizes e bases da educação nacional. Brasília: 1996. Disponível em: https://www.planalto.gov.br/ccivil_03/Leis/L9394.htm. Acesso em: 25 mai. 2019. . Ministério da Educação. Secretaria de Educação Básica. Diretrizes Curriculares Nacionais para a Educação Infantil. Brasília: MEC/SEB, 2010.

BARCELOS, Valdo Hermes de Lima. Educação Ambiental: sobre princípios, metodologias e atitudes. 4 ed. Petrópolis/RJ: Vozes, 2012.

BARDIN, L. Análise do Conteúdo. 4 ed. Lisboa: Edições 70, 2016.

BRZEZINSKI, Iria. Sujeitos sociais coletivos e a política de formação inicial e continuada emergencial de professores: contradições vs conciliações. Educação \& Sociedade. Campinas, v. 35, no. 129, p. 1241-1259, out-dez., 2014.

CAVALCANTE, Bruna Luana de Lima.; LIMA, Uirassú Tupinambá Silva de. Relato de experiência de uma estudante de Enfermagem em um consultório especializado em tratamento de feridas. Journal of Nursing and Health, Pelotas, Rio Grande do Sul, v. 1, n. 2, p. 94-103, 2012.

DE SOUZA, Vanessa Marcondes. A educação ambiental na formação acadêmica de professores. Conhecimento \& Diversidade, [S.1.], v. 4, n. 8, p. 104-114, mar. 2013. 
ELALI, Gleice Azambuja. O ambiente da escola - o ambiente na escola: uma discussão sobre a relação escola-natureza em educação infantil. Estudos de Psicologia (Natal), Natal, v. 8, n. 2, p. 309-319, Ago. 2003.

FAZENDA, Ivani. Práticas interdisciplinares na escola. Editora Cortez. 10 ed. 2005.

FONSECA, Luiz Almir Menezes. Metodologia científica ao alcance de todos. Manaus: Editora Valer, 2010.

MASULLO, Virginia Flora.; COELHO, Irene da Silva. As dificuldades dos professores da educação infantil: questões estruturais e pedagógicas. UNISANTA Humanitas, São Paulo, v. 4, n. 1, p. 72-97, 2015.

MORHY, Priscila Eduarda Dessimoni. O sentimento de pertença com crianças da educação infantil em relação a água em espaços educativos. 2018. 121 f. Dissertação (Mestrado em Educação em Ciências). Faculdade de Educação, Universidade do Estado do Amazonas (UEA), Amazonas, Manaus, 2018.

NEGRÃO, Felipe da Costa.; SARMENTO, Jackeline Ferreira.; GUEDES, Virgílio José Nazaré.; FACHÍN-TERÁN, Augusto. Livros Didáticos: uma análise a partir das tendências em educação e ensino de ciências. Areté - Revista Amazônica de Ensino de Ciências, Manaus, v.9, n.20, p. 21-31, Número especial, 2016.

REIGOTA, Marcos. O que é educação ambiental. São Paulo: Brasiliense, 2017. Meio ambiente e representação social. São Paulo: Cortez, 1995.

SANTOS, Eduarda Cristina Albuquerque dos. Alfabetização Científica: Um estudo na formação continuada de professores do programa Ciência na Escola no município de Manaus. Dissertação (Mestrado em Educação em Ciências na Amazônia) - Escola Normal Superior, Universidade do Estado do Amazonas, Manaus, 2018.

SELBACH, Selma. Ciências e Didática. Petrópolis, RJ: Vozes, 2010. (Coleção Como Bem Ensinar).

TRIVELATO, Sílvia Frateschi.; SILVA, Rosana Louro Ferreira. Ensino de Ciências. São Paulo: Cengage Learning, 2011.

VASCONCELOS, Elizandra Rego de. Questões socioambientais amazônicas, CTS e o ensino de ciências. REMEA - Revista Eletrônica do Mestrado em Educação Ambiental, [S.l.], v. 33, n. 3, p. 161-177, dez. 2016.

ZANON, Lenir Basso. Desafios da formação docente associados à reconstrução curricular na perspectiva da interdisciplinaridade e educação ambiental. In: GONÇALVES, Terezinha Valim Oliver.; MACÊDO, Francisco Cristiano da Silva.; SOUZA, Fábio Lustosa. Educação em Ciências e Matemáticas: debates contemporâneos sobre ensino e formação de professores. Porto Alegre: Penso, 2015. 
Submetido em: 31 de março de 2020 .

Aprovado em: 18 de julho de 2020. 